\title{
Selection of Maintenance Strategy For a Manufacturing Company with Fuzzy Moora Method
}

\author{
Nilsen Kundakcı ${ }^{1}$ \\ ${ }^{1}$ Pamukkale University, Department of Business Administration, Denizli, Turkey,
}

\begin{abstract}
.
In today's competitive environment, there is a pressure on companies for reducing costs and increasing the quality by providing on time delivery. Maintenance, plays an important role in reducing cost, improving quality, reducing failures, minimizing machine downtime, increasing productivity and as a result achieving objectives of company. The aim of this paper is to select best maintenance strategy for a manufacturing company by using Fuzzy MOORA (Multi Objective and Optimization on the Basis of Ratio Analysis) method. The selection of maintenance strategy is a multicriteria decision making (MCDM) problem. As this problem includes uncertainties and difficulty in evaluating alternatives and criteria with definite expressions, fuzzy MOORA method is proposed for selecting the best maintenance strategy. Implementation of the proposed method will assist the managers and decision makers in determining the most appropriate maintenance strategy for their company.
\end{abstract}

Keywords: MCDM, Fuzzy sets, Fuzzy MOORA, maintenance, strategy 


\section{Introduction}

Maintaining the production capability of a manufacturing company is a crucial function for the production system. Maintenance encompasses all the activities that relate to keeping facilities and equipment in good working order and making necessary repairs when breakdowns occur, so that the system can perform as intended (Stevenson, 2007).

Manufacturing companies have various problems that affect product quality, manufacturing costs and on time delivery of products to customers. One of these problems is maintenance strategy selection (Bashiri et al., 2011). Maintenance strategy has an important role in increasing quality and productivity, reducing cost, minimizing the machine downtime. By selecting the right maintenance strategy, manufacturing company can reach its objectives and optimize the processes. On the other hand it can be competitive and provide on time delivery.

There is a variety of strategies in maintenance management systems depending on the type of the industry of the company. These strategies can be categorized into four groups as corrective maintenance, time-based preventive maintenance, conditionbased maintenance and predictive maintenance (Wang et al., 2007; Bashiri et al., 2011). In corrective maintenance strategy, no maintenance activity is carried out until a failure occurs. Preventive time-based maintenance strategy is the strategy which is utilized before system failure to retain the system in the expected condition and performed based on a calendar schedule. Condition-based maintenance is a maintenance strategy that monitors the actual condition of equipment to decide what maintenance needs to be done by using real-time data to prioritize and optimize maintenance resources. Predictive maintenance is an attempt to determine when to perform preventive maintenance activities and based on historical data and analysis of the technical data to predict when an equipment or machine is about to breakdown (Stevenson, 2007).

Selection process of best maintenance strategy has multiple criteria to be considered. For this reason it can be handled with MCDM methods. In this study, maintenance strategy for a manufacturing company is selected with the help of fuzzy MOORA method which is an MCDM method. On the other hand, as this problem includes uncertainties and difficulty in evaluating alternatives and criteria with definite expressions fuzzy extension of MOORA method is used.

In the literature different methods were also proposed for maintenance strategy selection. These methods are summarized on Table 1. Also, comprehensive literature review on the use and application of MCDM methods in the field of maintenance strategy selection can be found in the paper of Shafiee (2015). 


\section{BUSINESS, MANAGEMENT \& ECONOMICS}

Table 1. Proposed methods for maintenance strategy selection in the literature

\begin{tabular}{|c|c|}
\hline Authors & Method \\
\hline Almedia and Bohoris (1995) & Decision theory \\
\hline Triantaphyllou et al. (1997) & $\begin{array}{l}\text { SAW (Simple Additive Weighting) } \\
\text { and AHP (Analytic Hierarchy Process) }\end{array}$ \\
\hline Bevilacqua and Braglia (2000) & AHP \\
\hline Al-Najjar and Alsyouf (2003) & Fuzzy MCDM \\
\hline Mechefske and Wang (2003) & Fuzzy linguistic approach \\
\hline Bertolini and Bevilacqua (2006) & Goal programming and AHP \\
\hline Wang et al. (2007) & Fuzzy AHP \\
\hline Pariazar et al. (2008) & $\begin{array}{l}\text { A combined approach based on improved AHP using rough set } \\
\text { theory and factor analysis }\end{array}$ \\
\hline lerace and Cavalieri (2008) & AHP and fuzzy MCDM methods \\
\hline Jafari et al. (2008) & Fuzzy Delphi method \\
\hline Cheng and Tsao (2010) & ANP (Analytic Network Process) \\
\hline Momeni et al. (2011) & $\begin{array}{l}\text { Fuzzy TOPSIS (Technique for Order Preference by Similarity to } \\
\text { Ideal Solution) }\end{array}$ \\
\hline Bashiri et al. (2011) & Fuzzy interactive linear assignment method \\
\hline Zhaoyang et al. (2011) & AHP \\
\hline Zaim et al. (2012) & AHP and ANP \\
\hline
\end{tabular}

The remainder of this study is organized as follows. In Section 2, fuzzy sets and fuzzy numbers are briefly defined. Fuzzy MOORA method is introduced and its steps are summarized in Section 3. Application of the proposed method in a manufacturing company is given in Section 4. Finally, conclusion and recommendations for future studies are given in Section 5.

\section{Fuzzy Sets and Fuzzy Numbers}

Fuzzy set theory was firstly introduced by Zadeh in 1965 for dealing with problems which includes uncertainty and vagueness. A fuzzy set is a class of objects with a continuum of grades of membership and it is characterized by a membership function that assigns to each object a grade of membership ranging between zero and one (Zadeh, 1965). Linguistic variable is a variable whose values are words or sentences in a natural or artificial language (Zadeh, 1975).

A fuzzy number is a generalization of a real number in the sense that it does not refer to one single value but rather to a connected set of possible values between 0 and 1 . It is possible to use different fuzzy numbers such as triangular fuzzy numbers, trapezoidal fuzzy numbers, sigmoidal fuzzy numbers etc. in the applications. But, it is convenient to work with triangular fuzzy numbers (TFNs) because of their 
computational simplicity. In this study, TFNs are adopted in fuzzy MOORA method. Triangular fuzzy numbers are defined by three real numbers, expressed as $(a, b, c)$. The parameters $a, b$, and $c$, respectively, indicate the smallest possible value, the most promising value, and the largest possible value that describe a fuzzy event. Membership function of a triangular fuzzy number can be given as seen in Eq. (1).

$$
\mu(x / \tilde{A})= \begin{cases}0, & x<a, \\ (x-a) /(b-a), & a \leq x \leq b, \\ (c-x) /(c-b), & b \leq x \leq c, \\ 0, & x>c\end{cases}
$$

If two positive triangular fuzzy numbers are defined as $\left(a_{1}, b_{1}, c_{1}\right)$ and $\left(a_{2}, b_{2}, c_{2}\right)$ then the operations of them can be given as:

$$
\begin{aligned}
& \left(a_{1}, b_{1}, c_{1}\right) \oplus\left(a_{2}, b_{2}, c_{2}\right)=\left(a_{1}+a_{2}, b_{1}+b_{2}, c_{1}+c_{2}\right) \\
& \left(a_{1}, b_{1}, c_{1}\right) \otimes\left(a_{2}, b_{2}, c_{2}\right)=\left(a_{1} \cdot a_{2}, b_{1} \cdot b_{2}, c_{1} \cdot c_{2}\right) \\
& k \otimes\left(a_{1}, b_{1}, c_{1}\right)=\left(k \cdot a_{1}, k \cdot b_{1}, k \cdot c_{1}\right) ; k>0 \text { and } k \in R
\end{aligned}
$$

\section{Fuzzy MOORA Method}

MOORA (Multi-Objective Optimization on the basis of Ratio Analysis) is the process of simultaneously optimizing two or more conflicting attributes (objectives) subject to certain constraints (Dey et al., 2012). MOORA method was firstly introduced by Brauers and Zavadskas in 2006. Later it is extended to fuzzy environment by Karande and Chakraborty (2012). Then fuzzy MOORA method has been applied to different areas in the literature. For instance it was applied to personnel selection (Baležentis et al., 2012), solve MCDM problems (Archana and Sujatha, 2012), supply chain strategy selection (Dey et al., 2012) best intelligent manufacturing system selection (Mandal and Sarkar, 2012), sector choosing for industrial engineering students (Akkaya et al., 2015), supplier selection (Pérez-Domínguez et al., 2015; Matawale et al., 2016; Arabsheybani et al., 2018), sustainable third-party reverse logistic provider selection (Mavi et al., 2017). Differently from these studies in the literature, in this paper, fuzzy MOORA method is proposed for maintenance strategy selection.

Steps of the fuzzy MOORA method can be summarized as (Karande and Chakraborty 2012):

Step 1. Firstly a committee of decision makers ( $\left.D M_{1}, D M_{2}, D M_{3}, . . D M_{k}\right)$ is formed. Then $m$ alternatives and $n$ evaluation criteria are determined by these decision makers. Later, alternatives are evaluated by using the linguistic variables given in Table 2. Then, criteria weights are determined by using linguistic variables seen in this table 


\section{$2^{\text {nd }}$ International Conference on BUSINESS, MANAGEMENT \& ECONOMICS}

(Chen, 2000). These linguistic variables are expressed in terms of fuzzy triangular numbers.

Table 2. Linguistic variables for evaluating alternatives and criteria

\begin{tabular}{lll}
\hline Linguistic Variables & TFNs for criteria & TFNs for alternatives \\
\hline Very Low $(\mathrm{VL})$ & $(0,0,0.1)$ & $(0,0,1)$ \\
Low (L) & $(0,0.1,0.3)$ & $(0,1,3)$ \\
Medium Low (ML) & $(0.1,0.3,0.5)$ & $(1,3,5)$ \\
Medium (M) & $(0.3,0.5,0.7)$ & $(3,5,7)$ \\
Medium High (MH) & $(0.5,0.7,0.9)$ & $(5,7,9)$ \\
High (H) & $(0.7,0.9,1)$ & $(7,9,10)$ \\
Very High (VH) & $(0.9,1,1)$ & $(9,10,10)$ \\
\hline
\end{tabular}

Step 2. After the alternatives and criteria are evaluated by decision makers, in order to reduce the evaluations of the decision makers for alternatives and criteria to a single value and construct the decision matrix Eq. 5 and 6 are used respectively.

$$
\tilde{x}_{i j}=\frac{1}{k}\left[\tilde{x}_{i j}^{1} \oplus \tilde{x}_{i j}^{2} \oplus \ldots \oplus \tilde{x}_{i j}^{k}\right]
$$

Here, $\tilde{x}_{i j}^{k}$ shows the evaluation rating of $i$ th $(i=1, \ldots, m)$ alternative under $j$ th $(j=1, \ldots, n)$ criterion by decision maker $k$.

$$
\tilde{w}_{j}=\frac{1}{k}\left[\tilde{w}_{j}^{1} \oplus \tilde{w}_{j}^{2} \oplus \ldots \oplus \tilde{w}_{j}^{k}\right]
$$

Here, $\tilde{w}_{j}^{k}$ indicates the evaluation result of the $k$ th decision maker for $j$ th criterion.

Step 3. After a single value is obtained for all criteria and alternatives, fuzzy decision matrix $\tilde{D}$ and fuzzy weight vector are formed as seen in Eq. 7.

$$
\tilde{D}=\left[\begin{array}{cccc}
\tilde{x}_{11} & \tilde{x}_{12} & \cdots & \tilde{x}_{1 n} \\
\tilde{x}_{21} & \tilde{x}_{22} & \cdots & \tilde{x}_{2 n} \\
\vdots & \vdots & \cdots & \vdots \\
\tilde{x}_{m 1} & \tilde{x}_{m 2} & \cdots & \tilde{x}_{m n}
\end{array}\right] \quad \tilde{W}=\left[\widetilde{w}_{1}, \widetilde{w}_{2}, \cdots \widetilde{w}_{n}\right]
$$

In this matrix $\tilde{x}_{i j}=\left(x_{i j}^{l}, x_{i j}^{m}, x_{i j}^{u}\right)$ and $x_{i j}^{l}, x_{i j}^{m}, x_{i j}^{u}$ denote the lower, middle and upper values of triangular fuzzy number $\tilde{x}_{i j}$.

Step 4. In this step, normalized fuzzy decision matrix $\widetilde{R}$ is formed.

$$
\widetilde{R}=\left[\widetilde{r}_{i j}\right]_{m x n}
$$




\section{$2^{\text {nd }}$ International Conference on BUSINESS, MANAGEMENT \& ECONOMICS}

Here $\tilde{r}_{i j}=\left(r_{i j}^{l}, r_{i j}^{m}, r_{i j}^{u}\right)$ and these values are obtained via Eq. 9, 10 and 11 respectively.

$$
\begin{gathered}
r_{i j}^{l}=\frac{x_{i j}^{l}}{\sqrt{\sum_{i=1}^{m}\left[\left(x_{i j}^{l}\right)^{2}+\left(x_{i j}^{m}\right)^{2}+\left(x_{i j}^{u}\right)^{2}\right]}} \\
r_{i j}^{m}=\frac{x_{i j}^{m}}{\sqrt{\sum_{i=1}^{m}\left[\left(x_{i j}^{l}\right)^{2}+\left(x_{i j}^{m}\right)^{2}+\left(x_{i j}^{u}\right)^{2}\right]}} \\
r_{i j}^{u}=\frac{x_{i j}^{u}}{\sqrt{\sum_{i=1}^{m}\left[\left(x_{i j}^{l}\right)^{2}+\left(x_{i j}^{m}\right)^{2}+\left(x_{i j}^{u}\right)^{2}\right]}}
\end{gathered}
$$

Step 5. In this step, weighted normalized decision matrix $\tilde{V}$ is obtained by using Eq. 12.

$$
\tilde{V}=\left[\tilde{v}_{i j}\right]_{m x n}
$$

Here, $\widetilde{v}_{i j}=\widetilde{r}_{i j}(.) \widetilde{w}_{j}$ and $\tilde{v}_{i j}=\left(v_{i j}^{l}, v_{i j}^{m}, v_{i j}^{u}\right)$.

Step 6. In this step, overall ratings of benefit and cost criteria are calculated for each alternative.

For benefit criteria, the overall ratings of an alternative for lower, middle and upper values are calculated via Eq. 13, 14 and 15 respectively.

$$
\begin{gathered}
s_{i}^{+l}=\sum_{j=1}^{n} v_{i j}^{l} \mid j \in J^{\max } \\
s_{i}^{+m}=\sum_{j=1}^{n} v_{i j}^{m} \mid j \in J^{\max } \\
s_{i}^{+u}=\sum_{j=1}^{n} v_{i j}^{u} \mid j \in J^{\max }
\end{gathered}
$$

For cost criteria, the overall ratings of an alternative for lower, middle and upper values are calculated by using Eq. 16, 17 and 18 respectively.

$$
s_{i}^{-l}=\sum_{j=1}^{n} v_{i j}^{l} \mid j \in J^{\min }
$$

\section{W w w. I C B M E C O N F. Org}




$$
\begin{aligned}
& s_{i}^{-m}=\sum_{j=1}^{n} v_{i j}^{m} \mid j \in J^{\min } \\
& s_{i}^{-u}=\sum_{j=1}^{n} v_{i j}^{u} \mid j \in J^{\min }
\end{aligned}
$$

Step 6. The overall performance index $\left(S_{\mathrm{i}}\right)$ for each alternative are determined in this step. For this, the defuzzified values of the overall ratings for benefit and cost criteria for each alternative are calculated with the help of the vertex method (Chen, 2000; Karende and Chakraborty, 2012) as seen in Eq. 19.

$$
S_{i}\left(s_{i}^{+}, s_{i}^{-}\right)=\sqrt{\frac{1}{3}\left[\left(s_{i}^{+l}-s_{i}^{-l}\right)^{2}+\left(s_{i}^{+m}-s_{i}^{-m}\right)^{2}+\left(s_{i}^{+u}-s_{i}^{-u}\right)^{2}\right]}
$$

Step 7. In the last step, alternatives are ranked according to their overall performance index values. The alternative with the highest overall performance index will be the best one.

\section{Application}

A manufacturing company located in Denizli, Turkey desires to select the most appropriate maintenance strategy for its company. There is a variety of strategies in maintenance management systems depending on the type of the industry of the company and these strategies are categorized into four groups. These four strategies are determined as alternatives: $A_{1}$ Corrective maintenance (CM), $A_{2}$ Preventive Timebased maintenance (PTBM), $A_{3}$ Condition-based maintenance (CBM) and $A_{4}$ Predictive maintenance (PDM). Later, ten criteria that are used in the evaluation of five maintenance strategies are determined by the decision makers. These criteria are; $C_{1}$ Safety of facility and equipment, $C_{2}$ Safety of personnel, $C_{3}$ Safety of environment, $C_{4}$ Acceptance by labors, $C_{5}$ Equipment and technology capability, $C_{6}$ Added value to product quality, $C_{7}$ Added value for equipment and personnel efficiency, $C_{8}$ Hardware cost, $C_{9}$ Software cost, $\mathrm{C}_{10}$ Personnel training cost.

After the criteria and alternatives are determined, they are evaluated by using the linguistic variables given in Table 1 by the decision makers. These evaluation results for criteria and alternatives are given on Table 3 and 4 respectively. 


\section{$2^{\text {nd }}$ International Conference on BUSINESS, MANAGEMENT \& ECONOMICS}

21 - 23 JUNE 2019

VIENNA, AUSTRIA

Table 3. Evaluation of criteria by decision makers

\begin{tabular}{lccc}
\hline \multicolumn{1}{c}{ Criteria } & \multicolumn{3}{c}{ Decision Makers } \\
\cline { 2 - 4 } & $\mathrm{DM}_{\mathbf{1}}$ & $\mathrm{DM}_{\mathbf{2}}$ & $\mathrm{DM}_{\mathbf{3}}$ \\
\hline $\mathrm{C}_{1}$ Safety of facility and equipment & $\mathrm{MH}$ & $\mathrm{H}$ & $\mathrm{VH}$ \\
$\mathrm{C}_{2}$ Safety of personnel & $\mathrm{VH}$ & $\mathrm{VH}$ & $\mathrm{H}$ \\
$\mathrm{C}_{3}$ Safety of environment & $\mathrm{ML}$ & $\mathrm{MH}$ & $\mathrm{M}$ \\
$\mathrm{C}_{4}$ Acceptance by labors & $\mathrm{H}$ & $\mathrm{ML}$ & $\mathrm{L}$ \\
$\mathrm{C}_{5}$ Equipment and technology capability & $\mathrm{L}$ & $\mathrm{M}$ & $\mathrm{M}$ \\
$\mathrm{C}_{6}$ Added value to product quality & $\mathrm{MH}$ & $\mathrm{VH}$ & $\mathrm{H}$ \\
$\mathrm{C}_{7}$ Added value for equipment and personnel efficiency & $\mathrm{H}$ & $\mathrm{H}$ & $\mathrm{VH}$ \\
$\mathrm{C}_{8}$ Hardware cost & $\mathrm{L}$ & $\mathrm{ML}$ & $\mathrm{MH}$ \\
C $_{9}$ Software cost & $\mathrm{L}$ & $\mathrm{M}$ & $\mathrm{MH}$ \\
$\mathrm{C}_{10}$ Personnel training cost & $\mathrm{M}$ & $\mathrm{ML}$ & $\mathrm{H}$ \\
\hline
\end{tabular}

Table 4. Evaluation of alternatives under each criterion by decision makers

\begin{tabular}{|c|c|c|c|c|}
\hline \multirow{2}{*}{ Criteria } & \multirow{2}{*}{ Alternatives } & \multicolumn{3}{|c|}{ Decision Makers } \\
\hline & & $\mathrm{DM}_{1}$ & $\mathrm{DM}_{2}$ & $\mathrm{DM}_{3}$ \\
\hline \multirow{4}{*}{$C_{1}$ Safety of facility and equipment } & $A_{1}$ & $\mathrm{~L}$ & $\mathrm{ML}$ & $M$ \\
\hline & $A_{2}$ & $\mathrm{M}$ & $\mathrm{M}$ & $\mathrm{ML}$ \\
\hline & $A_{3}$ & $\mathrm{MH}$ & $\mathrm{H}$ & M \\
\hline & $\mathrm{A}_{4}$ & $\mathrm{H}$ & VH & $\mathrm{H}$ \\
\hline \multirow{4}{*}{$C_{2}$ Safety of personnel } & $A_{1}$ & L & $\mathrm{M}$ & $\mathrm{ML}$ \\
\hline & $A_{2}$ & $\mathrm{MH}$ & $\mathrm{MH}$ & M \\
\hline & $A_{3}$ & $\mathrm{MH}$ & $\mathrm{H}$ & $\mathrm{MH}$ \\
\hline & $\mathrm{A}_{4}$ & $\mathrm{H}$ & $\mathrm{VH}$ & $\mathrm{H}$ \\
\hline \multirow{4}{*}{$\mathrm{C}_{3}$ Safety of environment } & $A_{1}$ & ML & $\mathrm{M}$ & $\mathrm{L}$ \\
\hline & $A_{2}$ & M & $\mathrm{MH}$ & $\mathrm{ML}$ \\
\hline & $A_{3}$ & $\mathrm{MH}$ & $\mathrm{H}$ & $\mathrm{MH}$ \\
\hline & $\mathrm{A}_{4}$ & $\mathrm{MH}$ & $\mathrm{H}$ & $\mathrm{H}$ \\
\hline \multirow{4}{*}{$\mathrm{C}_{4}$ Acceptance by labors } & $A_{1}$ & $\mathrm{H}$ & $\mathrm{MH}$ & $\mathrm{H}$ \\
\hline & $A_{2}$ & $\mathrm{MH}$ & M & M \\
\hline & $\mathrm{A}_{3}$ & ML & ML & $\mathrm{L}$ \\
\hline & $\mathrm{A}_{4}$ & M & $\mathrm{M}$ & $\mathrm{MH}$ \\
\hline \multirow{4}{*}{$C_{5}$ Equipment and technology capability } & $A_{1}$ & $\mathrm{~L}$ & $M L$ & M \\
\hline & $A_{2}$ & ML & M & $\mathrm{H}$ \\
\hline & $\mathrm{A}_{3}$ & M & $\mathrm{MH}$ & $\mathrm{MH}$ \\
\hline & $\mathrm{A}_{4}$ & $\mathrm{VH}$ & $\mathrm{H}$ & $\mathrm{H}$ \\
\hline \multirow{3}{*}{$\mathrm{C}_{6}$ Added value to product quality } & $A_{1}$ & $\mathrm{~L}$ & $M L$ & $\mathrm{ML}$ \\
\hline & $A_{2}$ & $\mathrm{MH}$ & $\mathrm{H}$ & $\mathrm{MH}$ \\
\hline & $A_{3}$ & M & $\mathrm{H}$ & $\mathrm{MH}$ \\
\hline
\end{tabular}




\section{$2^{\text {nd }}$ International Conference on BUSINESS, MANAGEMENT \& ECONOMICS}

21 - 23 JUNE 2019

VIENNA, AUSTRIA

\begin{tabular}{llccc} 
& $\mathrm{A}_{4}$ & $\mathrm{H}$ & $\mathrm{VH}$ & $\mathrm{H}$ \\
\hline & $\mathrm{A}_{1}$ & $\mathrm{VL}$ & $\mathrm{L}$ & $\mathrm{ML}$ \\
C7 Added value for equipment and personnel efficiency & $\mathrm{A}_{2}$ & $\mathrm{M}$ & $\mathrm{MH}$ & $\mathrm{M}$ \\
& $\mathrm{A}_{3}$ & $\mathrm{MH}$ & $\mathrm{H}$ & $\mathrm{MH}$ \\
& $\mathrm{A}_{4}$ & $\mathrm{H}$ & $\mathrm{VH}$ & $\mathrm{H}$ \\
\hline & $\mathrm{A}_{1}$ & $\mathrm{H}$ & $\mathrm{VH}$ & $\mathrm{H}$ \\
$\mathrm{C}_{8}$ Hardware cost & $\mathrm{A}_{2}$ & $\mathrm{MH}$ & $\mathrm{M}$ & $\mathrm{M}$ \\
& $\mathrm{A}_{3}$ & $\mathrm{H}$ & $\mathrm{H}$ & $\mathrm{MH}$ \\
& $\mathrm{A}_{4}$ & $\mathrm{H}$ & $\mathrm{MH}$ & $\mathrm{H}$ \\
\hline & $\mathrm{A}_{1}$ & $\mathrm{~L}$ & $\mathrm{ML}$ & $\mathrm{L}$ \\
C $_{9}$ Software cost & $\mathrm{A}_{2}$ & $\mathrm{ML}$ & $\mathrm{M}$ & $\mathrm{M}$ \\
& $\mathrm{A}_{3}$ & $\mathrm{M}$ & $\mathrm{MH}$ & $\mathrm{H}$ \\
& $\mathrm{A}_{4}$ & $\mathrm{VH}$ & $\mathrm{H}$ & $\mathrm{VH}$ \\
\hline & $\mathrm{A}_{1}$ & $\mathrm{~L}$ & $\mathrm{ML}$ & $\mathrm{M}$ \\
C $_{10}$ Personnel training cost & $\mathrm{A}_{2}$ & $\mathrm{ML}$ & $\mathrm{M}$ & $\mathrm{MH}$ \\
& $\mathrm{A}_{3}$ & $\mathrm{H}$ & $\mathrm{MH}$ & $\mathrm{H}$ \\
& $\mathrm{A}_{4}$ & $\mathrm{M}$ & $\mathrm{ML}$ & $\mathrm{M}$ \\
\hline
\end{tabular}

After the alternatives and criteria are evaluated by decision makers, evaluations of the decision makers for alternatives and criteria are reduced to a single value by using Eq. 5 and 6. Then, weights of the criteria are obtained as seen in Table 5, and fuzzy decision matrix is constructed as given in Table 6.

Table 5. Weights of the criteria

\begin{tabular}{lc}
\hline \multicolumn{1}{c}{ Criteria } & Weights \\
\hline$C_{1}$ Safety of facility and equipment & $(0.7,0.87,0.97)$ \\
$C_{2}$ Safety of personnel & $(0.83,0.97,1)$ \\
$C_{3}$ Safety of environment & $(0.3,0.5,0.7)$ \\
$C_{4}$ Acceptance by labors & $(0.27,0.43,0.6)$ \\
$C_{5}$ Equipment and technology capability & $(0.2,0.37,0.57)$ \\
$C_{6}$ Added value to product quality & $(0.7,0.87,0.97)$ \\
$C_{7}$ Added value for equipment and personnel efficiency & $(0.77,0.93,1)$ \\
$C_{8}$ Hardware cost & $(0.2,0.37,0.57)$ \\
$C_{9}$ Software cost & $(0.27,0.43,0.63)$ \\
$C_{10}$ Personnel training cost & $(0.37,0.57,0.73)$ \\
\hline
\end{tabular}


Table 6. Fuzzy decision matrix

\begin{tabular}{lcccc}
\hline & $\mathbf{A}_{1}$ & $\mathbf{A}_{2}$ & $\mathbf{A}_{3}$ & $\mathbf{A}_{4}$ \\
\hline $\mathbf{C}_{1}$ & $(1.33,3,5)$ & $(2.33,4.33,6.33)$ & $(5,7,8.67)$ & $(7.67,9.33,10)$ \\
$\mathbf{C}_{\mathbf{2}}$ & $(1.33,3,5)$ & $(4,33,6.33,8.33)$ & $(5.67,7.67,9.33)$ & $(7.67,9.33,10)$ \\
$\mathbf{C}_{\mathbf{3}}$ & $(1.33,3,5)$ & $(3,5,7)$ & $(5.67,7.67,9.33)$ & $(6.33,8.33,9.67)$ \\
$\mathbf{C}_{4}$ & $(6.33,8.33,9.67)$ & $(3.67,5.67,7.67)$ & $(0.67,2.33,4.33)$ & $(3.67,5.67,7.67)$ \\
$\mathbf{C}_{5}$ & $(1.33,3,5)$ & $(3.67,5.67,7.33)$ & $(4.33,6.33,8.33)$ & $(7.67,9.33,10)$ \\
$\mathbf{C}_{6}$ & $(0.67,2.33,4.33)$ & $(5.67,7.67,9.33)$ & $(5,7,8.67)$ & $(7.67,9.33,10)$ \\
$\mathbf{C}_{7}$ & $(0.33,1.33,3)$ & $(3.67,5.67,7.67)$ & $(5.67,7.67,9.33)$ & $(7.67,9.33,10)$ \\
$\mathbf{C}_{8}$ & $(7.67,9.33,10)$ & $(3.67,5.67,7.67)$ & $(6.33,8.33,9.67)$ & $(6.33,8.33,9.67)$ \\
$\mathbf{C}_{9}$ & $(0.33,1.67,3.67)$ & $(2.33,4.33,6.33)$ & $(5,7,8.67)$ & $(8.33,9.67,10)$ \\
$\mathbf{C}_{10}$ & $(1.33,3,4.33)$ & $(3,5,7)$ & $(6.33,8.33,9.67)$ & $(2.33,4.33,6.33)$ \\
\hline
\end{tabular}

Later, normalized fuzzy decision matrix is obtained as seen in Table 7. The values in this matrix are calculated by using Eq. 9, 10 and 11 .

Table 7. Normalized fuzzy decision matrix

\begin{tabular}{lcccc}
\hline & $\mathbf{A}_{1}$ & $\mathbf{A}_{2}$ & $\mathbf{A}_{3}$ & $\mathbf{A}_{4}$ \\
\hline $\mathbf{C}_{1}$ & $(0.06,0.13,0.22)$ & $(0.10,0.19,0.28)$ & $(0.22,0.31,0.39)$ & $(0.34,0.42,0.45)$ \\
$\mathbf{C}_{2}$ & $(0.05,0.12,0.21)$ & $(0.18,0.26,0.34)$ & $(0.23,0.32,0.38)$ & $(0.32,0.38,0.41)$ \\
$\mathbf{C}_{3}$ & $(0.06,0.13,0.22)$ & $(0.13,0.22,0.31)$ & $(0.25,0.34,0.42)$ & $(0.28,0.37,0.43)$ \\
$\mathbf{C}_{4}$ & $(0.30,0.40,0.46)$ & $(0.18,0.27,0.37)$ & $(0.03,0.11,0.21)$ & $(0.18,0.27,0.37)$ \\
$\mathbf{C}_{5}$ & $(0.06,0.13,0.22)$ & $(0.16,0.25,0.32)$ & $(0.19,0.28,0.37)$ & $(0.34,0.41,0.44)$ \\
$\mathbf{C}_{6}$ & $(0.03,0.10,0.18)$ & $(0.23,0.31,0.38)$ & $(0.20,0.29,0.35)$ & $(0.31,0.38,0.41)$ \\
$\mathbf{C}_{7}$ & $(0.01,0.06,0.13)$ & $(0.16,0.24,0.33)$ & $(0.24,0.33,0.40)$ & $(0.33,0.40,0.43)$ \\
$\mathbf{C}_{\mathbf{8}}$ & $(0.28,0.34,0.36)$ & $(0.13,0.21,0.28)$ & $(0.23,0.30,0.35)$ & $(0.23,0.30,0.35)$ \\
$\mathbf{C}_{9}$ & $(0.02,0.08,0.17)$ & $(0.11,0.20,0.29)$ & $(0.23,0.32,0.39)$ & $(0.38,0.44,0.45)$ \\
$\mathbf{C}_{10}$ & $(0.07,0.15,0.22)$ & $(0.15,0.25,0.36)$ & $(0.32,0.43,0.50)$ & $(0.12,0.22,0.32)$ \\
\hline
\end{tabular}

Then, weighted normalized decision matrix is obtained with the help of Eq. 12 as given on Table 8. 
Table 8. Weighted normalized fuzzy decision matrix

\begin{tabular}{lcccc}
\hline & $\mathbf{A}_{1}$ & $\mathbf{A}_{2}$ & $\mathbf{A}_{3}$ & $\mathbf{A}_{4}$ \\
\hline $\mathbf{C}_{1}$ & $(0.04,0.12,0.22)$ & $(0.07,0.17,0.28)$ & $(0.16,0.27,0.38)$ & $(0.24,0.36,0.43)$ \\
$\mathbf{C}_{2}$ & $(0.05,0.12,0.21)$ & $(0.15,0.25,0.34)$ & $(0.19,0.31,0.38)$ & $(0.26,0.37,0.41)$ \\
$\mathbf{C}_{3}$ & $(0.02,0.07,0.16)$ & $(0.04,0.11,0.22)$ & $(0.08,0.17,0.29)$ & $(0.08,0.19,0.30)$ \\
$\mathbf{C}_{4}$ & $(0.08,0.17,0.28)$ & $(0.05,0.12,0.22)$ & $(0.01,0.05,0.12)$ & $(0.05,0.12,0.22)$ \\
$\mathbf{C}_{5}$ & $(0.01,0.05,0.13)$ & $(0.03,0.09,0.18)$ & $(0.04,0.10,0.21)$ & $(0.07,0.15,0.25)$ \\
$\mathbf{C}_{6}$ & $(0.02,0.08,0.17)$ & $(0.16,0.27,0.37)$ & $(0.14,0.25,0.34)$ & $(0.22,0.33,0.40)$ \\
$\mathbf{C}_{7}$ & $(0.01,0.05,0.13)$ & $(0.12,0.23,0.33)$ & $(0.19,0.31,0.40)$ & $(0.25,0.38,0.43)$ \\
$\mathbf{C}_{8}$ & $(0.06,0.12,0.21)$ & $(0.03,0.08,0.16)$ & $(0.05,0.11,0.20)$ & $(0.05,0.11,0.20)$ \\
$\mathbf{C}_{9}$ & $(0,0.03,0.10)$ & $(0.03,0.08,0.18)$ & $(0.06,0.14,0.25)$ & $(0.10,0.19,0.29)$ \\
$\mathbf{C}_{10}$ & $(0.03,0.09,0.16)$ & $(0.06,0.15,0.26)$ & $(0.12,0.24,0.36)$ & $(0.04,0.13,0.24)$ \\
\hline
\end{tabular}

Later, overall ratings of benefit and cost criteria are calculated for each alternative. For benefit criteria, Eq. 13, 14 and 15 are used, whereas the overall ratings of an alternative for cost criteria are calculated by using Eq. 16, 17 and 18. At the end, overall performance index $\left(S_{i}\right)$ for each alternative are determined via Eq. 19. These obtained values are summarized at Table 9.

Table 9. Overall ratings of benefit and cost criteria and overall performance index

\begin{tabular}{cccc}
\hline & $s_{i}^{+}$ & $s_{i}^{-}$ & $S_{i}$ \\
\hline $\mathbf{A}_{1}$ & $(0.21,0.59,1.13)$ & $(0.08,0.24,0.47)$ & 0.43 \\
$\mathbf{A}_{2}$ & $(0.58,1.13,1.72)$ & $(0.11,0.31,0.60)$ & 0.85 \\
$\mathbf{A}_{3}$ & $(0.73,1.29,1.84)$ & $(0.22,0.49,0.81)$ & 0.81 \\
$\mathbf{A}_{4}$ & $(1.09,1.71,2.14)$ & $(0.19,0.43,0.72)$ & 1.22 \\
\hline
\end{tabular}

Finally, alternatives are ranked according to their overall performance index values. The ranking of the alternatives is $A_{4}>A_{2}>A_{3}>A_{1}$.

\section{Conclusion}

Increasing competition on industry forces manufacturing companies to give more importance to their plant, machinery and equipment. For this reason, companies wants to determine most cost effective and appropriate maintenance strategy for their manufacturing plant.

In the evaluation process of the maintenance strategy alternatives, fuzzy MOORA method is proposed as the evaluation criteria such as safety, acceptance of labors, product quality, equipment and personnel efficiency are difficult to express clearly in terms of numerical values. In fuzzy MOORA method, linguistic variables are used while evaluating the criteria and alternatives. 
As a result of the application of the fuzzy MOORA method in the manufacturing company, the ranking of the maintenance strategies was obtained as $A_{4}>A_{2}>A_{3}>A_{1}$ and predictive maintenance strategy was determined as the most appropriate maintenance strategy for the company. So it was advised to the decision makers to use predictive maintenance strategy in order to achieve their company objectives such as increasing product quality and productivity, reducing cost and the machine downtime. It was also advised that to determine their maintenance plans based on historical and technical data of equipment or machine breakdowns.

The proposed approach can assist managers in evaluating maintenance strategies and selecting the most appropriate one for the manufacturing company. Selecting the best maintenance strategy provides the company to increase product quality, plant safety and efficiency and to decrease manufacturing cost.

For further studies it can be recommended that maintenance strategy selection problem can be solved with other fuzzy MCDM methods and the obtained results can be compared.

\section{Acknowledgements}

This work was supported by the Department of Scientific Research Projects, Pamukkale University.

\section{References}

[1]. Akkaya, G. Turanoğlu, B. and Öztaş, S. (2015). “An integrated fuzzy AHP and fuzzy MOORA approach to the problem of industrial engineering sector choosing," Expert Systems with Applications, vol. 42, pp. 9565-9573.

[2]. Almedia, A.T. and Bohoris G.A. (1995). "Decision theory in maintenance decision making," Quality in Maintenance Engineering, vol. 1 (1), pp. 39-45.

[3]. Al-Najjar, B. and Alsyouf, I. (2003). "Selecting the most efficient maintenance approach using fuzzy multiple criteria decision making," International Journal of Production Economics, vol. 84, pp. 85-100.

[4]. Arabsheybani, A., Paydar, M. M. and Safaei A. S. (2018). "An integrated fuzzy MOORA method and FMEA technique for sustainable supplier selection considering quantity discounts and supplier's risk," Journal of Cleaner Production, vol. 190, pp. 577-591.

[5]. Archana, M. and Sujatha, V. (2012). "Application of fuzzy MOORA and GRA in multi-criterion decision making problems," International Journal of Computer Applications, vol. 53 (9), pp. 46-50.

[6]. Baležentis, A., Baležentis, T. and Brauers, W. K. M. (2012). "Personnel selection based on computing with words and fuzzy MULTIMOORA," Expert Systems with Applications, vol. 39 (9), pp. 7961-7967. 
[7]. Bashiri, M., Badri, H. and Hejazi, T. H. (2011). "Selecting optimum maintenance strategy by fuzzy interactive linear assignment method," Applied Mathematical Modelling, vol. 35, pp. 152-164.

[8]. Bertolini, M. and Bevilacqua, M. (2006). "A combined goal programming-AHP approach to maintenance selection problem," Reliability Engineering and System Safety, vol. 91(7), pp. 839-848.

[9]. Bevilacqua, M. and Braglia, M. (2000). "The analytic hierarchy process applied to maintenance strategy selection," Reliability Engineering and System Safety, vol. 70, pp. 71-83.

[10]. Brauers, W. K. M. and Zavadskas, E. K. (2006). "The MOORA method and its application to privatization in a transition economies," Control and Cybernetics, vol. 35 (2), pp. 445-469.

[11]. Chen, C. T. (2000). "Extensions of the TOPSIS for group decision-making under fuzzy environment," Fuzzy Sets and Systems, vol.114, pp. 1-9.

[12]. Cheng, Y.-H. and Tsao, H-L. (2010). "Rolling stock maintenance strategy selection, sparesparts' estimation, and replacements' interval calculation," International Journal of Production Economics, vol. 128, pp. 404-412.

[13]. Dey, B., Bairagi, B., Sarkar, B. and Sanyal, S. (2012). "A MOORA based fuzzy multi-criteria decision making approach for supply chain strategy selection," International Journal of Industrial Engineering Computations, vol.3, pp. 649662.

[14]. lerace, S. and Cavalieri, S. (2008). Maintenance strategy selection: a comparison between fuzzy logic and analytic hierarchy process. 9th IFAC Workshop on Intelligent Manufacturing Systems. Szczecin, Poland, pp. 228-233.

[15]. Jafari, A., Jafarian, M. Zareei, A. and Zaerpour, F. (2008). "Using fuzzy Delphi method in maintenance strategy selection problem," Journal of Uncertain Systems, vol. 2 (4), pp. 289-298.

[16]. Karande, P. and Chakraborty, S. (2012). "A fuzzy-MOORA approach for ERP system selection," Decision Science Letters, vol.1, pp.11-22.

[17]. Mandal U. K. and Sarkar, B. (2012). "Selection of best intelligent manufacturing system (IMS) under fuzzy MOORA conflicting MCDM environment," International Journal of Emerging Technology and Advanced Engineering, Vol. 2 (9), pp. 301-310.

[18]. Matawale, C. R., Datta, S. and Mahapatra, S.S. (2016). "Supplier selection in agile supply chain: Application potential of FMLMCDM approach in comparison with Fuzzy-TOPSIS and Fuzzy-MOORA", Benchmarking: An International Journal, Vol. 23 (7), pp. 2027-2060.

[19]. Mavi, R. K., Goh, M. and Zarbakhshnia, N. (2017). "Sustainable third-party reverse logistic provider selection with fuzzy SWARA and fuzzy MOORA in plastic industry," The International Journal of Advanced Manufacturing Technology, vol. 91, pp. 2401-2418. 
[20]. Mechefske, C.K. and Wang, Z. (2003). "Using fuzzy linguistics to select optimum maintenance and condition monitoring strategies," Mechanical Systems and Signal Processing, vol. 17 (2), pp. 305-316.

[21]. Momeni, M., Fathi, M. R., Zarchi, M. K. and Azizollahi, S. (2011). "A fuzzy TOPSISbased approach to maintenance strategy selection: a case study," Middle-East Journal of Scientific Research, vol. 8 (3), pp. 699-706.

[22]. Pariazar, M., Shahrabi, J., Zaeri, M.S. and Parhizi, S. (2008). "A combined approach for maintenance strategy selection," Journal of Applied Sciences, vol. 8 (23), pp. 4321-4329.

[23]. Pérez-Domínguez, L., Alvarado-Iniesta, A., Rodríguez-Borbón, I. and VergaraVillegas, O. (2015). "Intuitionistic fuzzy MOORA for supplier selection," DYNA, vol. 82 (191), pp. 34-41.

[24]. Shafiee, M. (2015). "Maintenance strategy selection problem: an MCDM overview," Journal of Quality in Maintenance Engineering, vol. 21 (4), pp. 378402.

[25]. Stevenson, W.J. (2007). Operations Management, New York: McGraw-Hill/Irwin.

[26]. Triantaphyllou, E. Kovalerchuk, B. Mann, L. and Knapp G., (1997). “Determining the most important criteria in maintenance decision making," Journal of Quality in Maintenance Engineering, vol. 3(1), pp. 16-28.

[27]. Wang, L., Chu, J. and Wu, J. (2007). "Selection of optimum maintenance strategies based on a fuzzy analytic hierarchy process," International Journal of Production Economics, vol. 107, pp. 151-163.

[28]. Zadeh, L. A. (1965). "Fuzzy sets," Information and Control, vol. 8, pp. 338-353.

[29]. Zadeh, L. A. (1975). "The concept of a linguistic variable and its application to approximate reasoning-I," Information Sciences, vol. 8, pp. 199-249.

[30]. Zaim, S., Turkyılmaz, A., Acar, M.F. Al-Turki, U. and Demirel, O. F. (2012). "Maintenance strategy selection using AHP and ANP algorithms: a case study," Journal of Quality in Maintenance Engineering, vol. 18 (1), pp. 16-29.

[31]. Zhaoyang, T., Jianfeng, L., Zongzhi, W., Jianhu, Z. and Weifeng, H. (2011). "An evaluation of maintenance strategy using risk based inspection," Safety Science, vol. 49, pp. 852-860. 